\title{
Review
}

\section{Sialorrhea in Patients with Parkinson's Disease: Safety and Administration of Botulinum Neurotoxin ${ }^{1}$}

\author{
Gustav Egevad, Valentina Yankova Petkova and Ole Jakob Vilholm* \\ Department of Neurology, Lillebaelt Hospital, Vejle, Denmark
}

\begin{abstract}
Sialorrhea may present as a troublesome symptom in patients suffering from Parkinson's disease. Current options for treatment include anticholinergic drugs, irradiation, surgery, oral-motor and behavioural therapies, and injection of botulinum neurotoxin (BoNT) in the salivary glands. The aim of this study is to evaluate the safety and administration of BoNT as a treatment for sialorrhea in patients with Parkinson's disease (PD) based on a review of the studies conducted so far in this field. A PubMed search was conducted using the major keywords sialorrhea, botulinum neurotoxin, botulinum toxin and Parkinson's disease. The literature search identified 12 articles, which were selected for further analysis. Few adverse effects were described in the studies included in this present review. Various treatment strategies, including different medication dosages, were applied in the studies. BoNT treatment is safe for sialorrhea in patients with PD. Positive effect is well documented, and there have been relatively few reported adverse effects, which have been mild and transient. Based on this review, a treatment algorithm is proposed. Ultrasound guidance may not be necessary when injecting the parotid gland but may improve the effect and safety of administration, especially when injecting the submandibular glands.
\end{abstract}

Keywords: Parkinson's disease, sialorrhea, drooling, botulinum neurotoxin, treatment

\section{INTRODUCTION}

Parkinson's disease (PD) is one of the most common degenerative disorders of the central nervous system with an overall incidence of 118 per 100,000 personyears [1]. PD is clinically diagnosed based on motor symptoms: bradykinesia, rigidity, $4-6 \mathrm{~Hz}$ rest tremor and postural instability [2]. However, the patient may also suffer from non-motor symptoms such as sialorrhea, which occurs in 32 to $74 \%$ of PD patients [3]. Sialorrhea is classified as primary or secondary. Primary sialorrhea occurs when there is excessive

\footnotetext{
${ }^{1}$ Review of the literature and a proposal for a treatment algorithm.

*Correspondence to: Ole Jakob Vilholm, Department of Neurology, Lillebaelt Hospital, Vejle, Denmark. Tel.: +45 794055 00; Fax: +45 794068 63; E-mail: ole.vilholm@rsyd.dk.
}

production of saliva, while secondary sialorrhea is the result of disorders of the coordinated activity of the orofacial and palatolingual muscles decreasing the clearance of saliva [4]. Research has shown that saliva production is lower in PD patients compared to healthy controls and that sialorrhea is of a secondary nature $[5,6]$.

In humans, saliva production is primarily mediated by the submandibular, sublingual and parotid glands, which are innervated by the parasympathetic nervous system. When not stimulated, saliva is produced continuously, mainly by the sublingual and submandibular glands [7]. In the stimulated state, the salivary flow increases up to 5-fold, and this increase is mediated by the parotid gland [7]. Sialorrhea has been shown to have a negative effect on social functioning and may lead to aspiration pneumonia and choking $[6,8]$. 
Current options for treatment of sialorrhea in patients suffering from PD include anticholinergic drugs, treatment with botulinum neurotoxin (BoNT), irradiation, surgery and oral-motor and behavioural therapies [9]. Lately, a german guideline for the treatment of sialorrhea has been proposed [10].

BoNT as a possible treatment for sialorrhea was first proposed by Bushara et al. in 1997. These researchers described injection of BoNT into the parotid gland [11]. Intraglandular administration of BoNT inhibits the release of presynaptic acetylcholine at the neurosecretory junctions of the salivary glands [12]. Until now, 7 serotypes of BoNT had been identified (serotypes A-G) [9]. Four different preparations of BoNT have been approved for clinical use: OnabotulinumtoxinA (A/Ona, brand name: BOTOX ${ }^{\circledR}$ ); AbobotulinumtoxinA (A/Abo, brand name: Dysport ${ }^{\circledR}$ ); IncobotulinumtoxinA (A/Inco, brand name: XEOMIN $\left.{ }^{\circledR}\right)$ and RimabotulinumtoxinB (B/Rima, brand name: Myobloc ${ }^{\circledR} /$ Neurobloc ${ }^{\circledR}$ ).

Since the introduction in 1997, several clinical studies have been conducted on the BoNT treatment of sialorrhea in patients suffering from neurodegenerative diseases like PD and Amyotrophic Lateral Sclerosis (ALS). Recently, a review with a proposal for tailored treatment for BoNT treatment of sialorrhea in ALS has been published [13]. However, a review conducted solely on this treatment modality in PD patients has not yet been conducted. Thus, this review was set up to evaluate the efficacy and safety of the administration of BoNT for the treatment of sialorrhea in patients suffering from PD.

BoNT treatment of sialorrhea has not yet been approved by the FDA, but an approval study is at the moment ongoing.

A PubMed search of English language publications was conducted using the keywords sialorrhea, botulinum toxin, botulinum neurotoxin and Parkinson's disease. The clinical studies from 2003 to date on BoNT treatment of sialorrhea related to PD were included in the review. The American Academy of Neurology (AAN) Classification of Evidence for Therapeutic Intervention was applied for classification of the individual studies according to level of evidence [14].

\section{DESCRIPTION}

Twelve studies fulfilled the inclusion criteria. Of these studies, 7 were conducted on PD patients exclusively [15-21], and 5 included PD patients as well as patients with other diseases [22-26]. The 12 studies are listed in Table 1.

\section{Effect of treatment}

The studies reported several methods of evaluation for the effect of BoNT. The drooling score and drooling frequency score (DS-DF), the visual analogue scale (VAS) and cotton-roll weight were the most frequently used methods of evaluation. Overall, the studies reported a positive effect of BoNT on sialorrhea in $50-100 \%$ of the patients.

Mancini et al. reported a positive effect in $50 \%$ of the patients, with positive effect defined as a 2point improvement on the drooling scale score [25]. The other studies applied a definition of any improvement in the subjective and/or objective measurements compared to the baseline. Svetel et al. reported a nonresponder rate of $32 \%$ [22]. Overall, the duration of the effect varied from 1 to 6 months.

\section{Adverse effects}

Several adverse effects (AEs) were reported in the studies, including dry mouth, alterations in saliva composition and mild swallowing and chewing difficulties. The AEs were generally reported as mild and transient, and no severe AEs were reported among the PD patients in the studies.

\section{Choice of glands}

In 8 studies, BoNT was injected bilaterally into the parotid gland; in 4 studies, injection was performed bilaterally in the parotid and submandibular glands. The number of injection sites in each parotid gland varied from 1 to 2 , whereas only 1 site was used for the submandibular glands.

\section{Ultrasound guidance}

In 7 studies, the injection sites were located by ultrasound guidance, and anatomical landmarks were used for guidance in the other 5 studies. In the study by Svetel et al. similar response rates to BoNT treatment were observed in the 2 groups of patients with and without ultrasound guidance [15]. However, in the study done by Dogu et al. ultrasound-guided BoNT injections were superior to non-ultrasound-guided injections based on the quantitative saliva measurements [17]. Injection was only performed in the parotid gland in these 2 studies. 


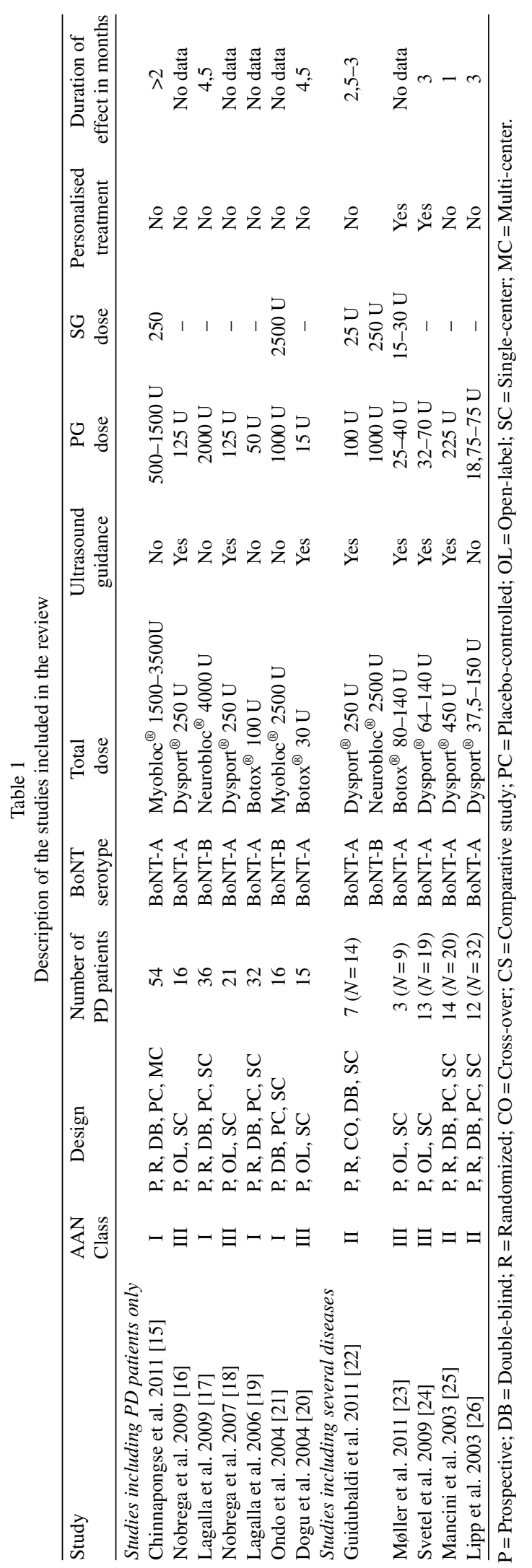




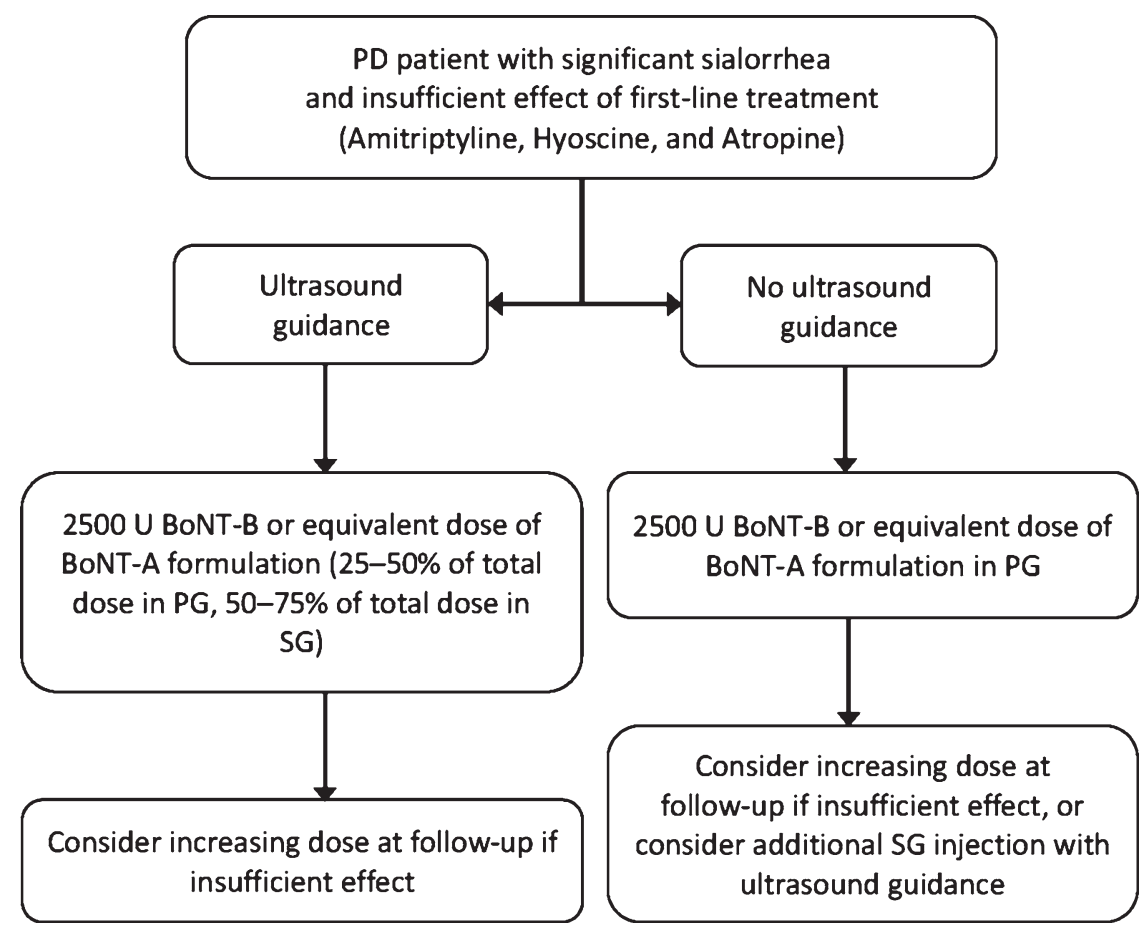

Fig. 1. Algorithm for BoNT treatment of sialorrhea in patients suffering from Parkinson's disease. (PG: Parotid gland, SG: Submandibular gland).

\section{BoNT type-A versus BoNT type-B}

One study compared the effects of the two serotypes [19]. In this study, the serotypes had similar effectiveness and safety. However, BoNT type-B demonstrated a shorter latency from the time of injection to onset of effect and a slightly longer duration of the effect.

\section{Dose of BoNT}

BoNT type-A was tested in the range of 64-450 $\mathrm{U} A / A b o$ and in the range of $25-100 \mathrm{U}$ A/Ona as total dose. BoNT type-B was tested in the range of 1500-3500 U B/Rima. For B/Rima, the best results were seen at the higher dose (3500 U).

\section{CONCLUSION}

\section{Effect of treatment}

Existing studies on BoNT treatment of sialorrhea in patients with PD differ considerably in methodology. Thus, exact comparison between the studies is difficult, especially when evaluating the effect of BoNT treatment.

Of the studies conducted exclusively on PD patients, 4 were carried out as double-blinded, randomized, placebo-controlled studies $[15,17,19,20]$. These studies all reported a positive effect of BoNT treatment and provided high-level evidence of the effect of BoNT treatment on sialorrhea in PD patients.

\section{Adverse effects}

Only mild, transient adverse effects were seen among the PD patients in the studies included in this review. However, the spread of BoNT to nearby structures has been reported in other studies [27, 28]. Unlike ALS patients, most of the PD patients who develop sialorrhea do not have the assistance of a feeding tube or ventilator. Special precautions must therefore be taken to prevent dysphagia and breathing difficulties when applying BoNT treatment for sialorrhea to PD patients.

\section{Administration}

Based on the research, the submandibular and parotid glands should be injected to achieve the best effect in the fasting state [7]. This was also demonstrated in a study on sialorrhea in cerebral palsy [29]. Therefore, it is recommended to inject the submandibular glands when treatment of the parotid gland alone is insufficient. Injection should be done bilaterally. 


\section{Ultrasound guidance}

All of the studies included in this review applied injection of the parotid gland, and 5 studies did not incorporate ultrasound guidance. Hence, it can be concluded that injection of the parotid gland can be carried out safely without ultrasound injection. Only 4 studies included submandibular gland injection, and 2 of these did not apply ultrasound guidance. Therefore, there is not sufficient evidence supporting the safety and effectiveness of injecting the submandibular glands without the use of ultrasound guidance.

\section{CONCLUDING REMARKS}

BoNT treatment is safe for treating sialorrhea in patients with PD. This treatment has a welldocumented effect and few adverse effects, which are mild and transient. Based on this review of the literature, an algorithm is proposed to help select the best approach to treatment of the individual patient (Fig. 1). In this algorithm, it is recommended that injection be limited to the parotid gland if ultrasound is not available. Careful information on the possible adverse effects should be given to the patient before initializing the treatment. Ultrasound guidance may not be necessary when injecting the parotid gland alone, but it may improve the safety and effectiveness of the treatment, especially when injecting the submandibular glands.

\section{ACKNOWLEDGMENTS}

None.

\section{CONFLICT OF INTERESTS}

Gustav Egevad and Valentina Yankova Petkova report no conflict of interests. Ole Jakob Vilholm has participated in studies and/or received grants and funding from the following companies: Allergan, Ipsen and Eisai Inc.

\section{REFERENCES}

[1] Horsfall L, Petersen I, Walters K, \& Schrag A (2013) Time trends in incidence of Parkinson's disease diagnosis in UK primary care. J Neurol, 260(5), 1351-1357.

[2] UK Parkinson's Disease Society Brain Bank's clinical criteria for the diagnosis of probable Parkinson's disease. NICE Clinical Guidelines, No. 35 (2006) National Collaborating Centre for Chronic Conditions (UK). London: Royal College of Physicians (UK).
[3] Kalf JG, de Swart BJ, Borm GF, Bloem BR, \& Munneke M (2009) Prevalence and definition of drooling in Parkinson's disease: A systematic review. J Neurol, 256(9), 1391-1396.

[4] Meningaud JP, Pitak-Arnop P, Chikhani L, \& Bertrand JC (2006) Drooling of saliva: A review of the etiology and management options. Oral Surg Med Oral Pathol Radiol Endod, 101, 48-57.

[5] Proulx M, de Courval FP, Wiseman M, \& Panisset M (2005) Salivary production in Parkinson's Disease. Movement Disorders, 20, 204-207.

[6] Nóbrega AC, Rodrigues B, Torres AC, Scarpel RD, Neves CA, \& Melo A (2008) Is drooling secondary to a swallowing disorder in patients with Parkinson's disease? Parkinsonism Relat Disord, 14(3), 243-245.

[7] Sreebny LM (2000) Saliva in health and disease: An appraisal and update. Int Dent J, 50, 140-161.

[8] Kalf JG, Smith AM, Bloem BR, Zwarts MJ, \& Munneke M (2007) Impact of drooling in Parkinson's disease. J Neurol, 254(9), 1227-1232.

[9] Potulska A, \& Friedman A (2005) Controlling sialorrhea: A review of available treatment options. Expert Opin Pharmacother, 6(9), 1551-1554.

[10] Steffen A, Beutner D, Hakim S, Jost W, Kahl KG, Laskawi R, Lencer R, Mall V, Mehrhoff FW, Meyners T, Schönweiler R, Schröder S, Schröter-Morasch H, Schuster M, Steinlechner S, Winterhoff J, Zenk J, \& Guntinas-Lichius O (2013) AWMF. Hypersalivation - inauguration of the S2k Guideline (AWMF) in short form. Laryngorhinootologie 92(8), 515-522.

[11] Bushara KO (1997) Sialorrhea in amyotrophic lateral sclerosis: A hypothesis of a new treatment-botulinumtoxin A injections of the parotid glands. Med Hypotheses, 48(4), 337339.

[12] Intiso D (2012) Therapeutic use of botulinum toxin in neurorehabilitation. J Toxicol 2012, article no. 802893.

[13] Stokholm MG, Bisgård C, \& Vilholm OJ (2013 Dec) Safety and administration of treatment with botulinum neurotoxin for sialorrhoea in ALS patients: Review of the literature and a proposal for tailored treatment. Amyotroph Lateral Scler Frontotemporal Degener, 14(7-8), 516-520.

[14] AAN (American Academy of Neurology) (2011) Clinical practice Guideline Process Manual, Ed. St. Paul, MN: The American Acadamy of Neurology.

[15] Chinnapongse R, Gullo K, Nemeth P, Zhang Y, \& Griggs L (2012) Safety and efficacy of botulinum toxin type B for treatment of sialorrhea in parkinson's disease: A prospective double-blind trial. Mov Disord, 27(2), 219-226.

[16] Nóbrega AC, Rodreigues B, \& Melo A (2009) Does botulinum toxin injection in parotid glands interfere with the swallowing dynamics of Parkinson's disease patients? Clin Neurol Neurosurg, 111(5), 430-432.

[17] Lagalla G, Millevolte M, Capecci M, Provinciali L, \& Ceravolo MG (2009) Long-lasting benefits of botulinum toxin type B in Parkinson's disease-related drooling. J Neurol, 256(4), 563-567.

[18] Nóbrega AC, Rodrigues B, Torres AC, Enzo A, \& Melo A (2007) Does botulinum toxin decrease frequency and severity of sialorrhea in Parkinson's disease? J Neurol Sci 253(1-2), 85-87.

[19] Lagalla G, Millevolte M, Capecci M, Provinciali L, \& Ceravolo MG (2006) Botulinum Toxin Type A for Drooling in Parkinson's Disease: A Double-Blind, Randomized, PlaceboControlled Study. Mov Disord, 21(5), 704-707.

[20] Dogu O, Apaydin D, Sevim S, Talas DU, \& Aral M (2004) Ultrasound-Guided versus 'blind' intraparotid injections of 
botulinum toxin-A for the treatment of sialorrhea in patients with Parkinson's disease. Clin Neurol Neurosurg, 106(2), 9396.

[21] Ondo WG, Hunter C, \& Moore W (2004) A double-blind placebo-controlled trial of botulinum toxin B for sialorrhea in Parkinson's disease. Neurology, 62(1), 37-40.

[22] Guidubaldi A, Fasano A, Ialongo T, Piano C, Pompili M, Mascianá R, Siciliani L, Sabatelli M, \& Bentivoglio AR (2011) Botulinum toxin A versus B in sialorrhea: A prospective, randomized, double-blind, crossover pilot study in patients with amyotrophic lateral sclerosis or Parkinson's disease. Mov Disord, 26(2), 313-319.

[23] Møller E, Karlsborg M, Bardow A, Lykkeaa J, Nissen FH, \& Bakke M (2011) Treatment of severe drooling with botulinum toxin in amyotrophic lateralsclerosis and Parkinson's disease: Efficacy and possible mechanism. Acta Odontol Scand, 69(3), 151-157.

[24] Svetel M, Vasić M, Dragasević N, Pekmezović T, Petrović I, \& Kostić V (2009) Botulinum toxin in the treatment of sialorrhea. Vojnosanit Pregl, 66(1), 9-12.
[25] Mancini F, Zangaglia R, Silvano C, Sommarsuga MG, Martignoni E, Nappi G, \& Pacchetti C (2003) Double-Blind, Placebo-Controlled Study to Evaluate the Efficacy and Safety of Botulinum Toxin Type A in the Treatment of Drooling in Parkinson's ism. Mov Disord, 18(6), 685-688.

[26] Lipp A, Trottenberg T, Chink T, Kupsh A, \& Arnold G (2003) A randomized trial of botulinum toxin A for treatment of drooling. Neurology, 61(9), 1279-1281.

[27] Meijer JW, van Kuijk AA, Geurts AC, Schelhaas HJ, \& Zwarts MJ (2008) Acute deterioration of bulbar function after botulinum toxin treatment for sialorrhoea in amyotrophic lateral sclerosis. Am J Phys Med Rehabil, 87, 321-324.

[28] Tan EK, Lo YL, Seah A, \& Auchus AP (2001) Recurrent jaw dislocation after botulinum toxin treatment for sialorrhoea in amyotrophic lateral sclerosis. J Neurol Sci, 190, 95-97.

[29] Suskind DL, \& Tilton A (2002) Clinical study of botulinum-A toxin in the treatment of sialorrhea in children with cerebral palsy. Laryngoscope, 112, 73-81. 